\title{
The Meaning in Life Questionnaire: Assessing the Presence of and Search for Meaning in Life
}

\author{
Michael F. Steger and Patricia Frazier \\ University of Minnesota-Twin Cities Campus
}

\author{
Shigehiro Oishi \\ University of Virginia
}

\author{
Matthew Kaler \\ University of Minnesota-Twin Cities Campus
}

\begin{abstract}
Counseling psychologists often work with clients to increase their well-being as well as to decrease their distress. One important aspect of well-being, highlighted particularly in humanistic theories of the counseling process, is perceived meaning in life. However, poor measurement has hampered research on meaning in life. In 3 studies, evidence is provided for the internal consistency, temporal stability, factor structure, and validity of the Meaning in Life Questionnaire (MLQ), a new 10-item measure of the presence of, and the search for, meaning in life. A multitrait-multimethod matrix demonstrates the convergent and discriminant validity of the MLQ subscales across time and informants, in comparison with 2 other meaning scales. The MLQ offers several improvements over current meaning in life measures, including no item overlap with distress measures, a stable factor structure, better discriminant validity, a briefer format, and the ability to measure the search for meaning.
\end{abstract}

Keywords: meaning in life, purpose in life, measurement, scale construction, well-being

In recent years the construct of meaning in life has received renewed attention and legitimacy, perhaps in conjunction with a growing focus on positive traits and psychological strengths (Ryan \& Deci, 2001; Seligman \& Csikszentmihalyi, 2000). Invariably, meaning in life is regarded as a positive variable - an indicator of well-being (Ryff, 1989), a facilitator of adaptive coping (Park \& Folkman, 1997), or a marker of therapeutic growth (Crumbaugh \& Maholick, 1964; Frankl, 1965). A recent report in the Journal of Counseling Psychology advocated for the understanding and assessment of well-being variables such as meaning in life in order to promote client growth and recovery (Lent, 2004). Despite substantial progress over the 40-year history of empirical research on meaning and the resurgence presently occurring, existing research seems unable to answer many fundamental questions about the construct. We argue that better measurement will help advance this research by providing a measure of therapeutic outcome and

Michael F. Steger, Patricia Frazier, and Matthew Kaler, Department of Psychology, University of Minnesota-Twin Cities Campus; Shigehiro Oishi, Department of Psychology, University of Virginia.

This research was supported by a Harrison Gough Graduate Research Grant to Michael F. Steger from the University of Minnesota. Portions of this article were presented at the 2nd International Positive Psychology Summit, October 2003, Washington, DC, and at the Seventh European Conference on Psychological Assessment, March 2004, Málaga, Spain.

We thank Brandon Sullivan and Andrew Tix for their collection of some of the data used in these studies. We also thank Mark Snyder and Todd Kashdan for their helpful comments on a draft of this article.

Correspondence concerning this article should be addressed to Michael F. Steger, University of Minnesota, Department of Psychology, N218 Elliott Hall, 75 East River Road, Minneapolis, MN 55455. E-mail: steg0043@umn.edu personal growth that counseling psychologists historically have been interested in, particularly those influenced by the humanistic tradition of promoting growth and not simply decreasing symptoms. The purpose of the present research was to develop an improved measure of meaning in life.

\section{Overview of Meaning in Life Literature}

The definition of meaning in life varies throughout the field, ranging from coherence in one's life (Battista \& Almond, 1973; Reker \& Wong, 1988) to goal directedness or purposefulness (e.g., Ryff \& Singer, 1998) to "the ontological significance of life from the point of view of the experiencing individual" (Crumbaugh \& Maholick, 1964, p. 201). Others offer semantic definitions (e.g., "What does my life mean?"; Baumeister, 1991; Yalom, 1980). Likewise, there is diversity in perspectives regarding how to achieve meaning in life. Because there is no universal meaning that can fit everyone's life (Frankl, 1965), each person must create meaning in his or her own life (Battista \& Almond, 1973), whether through the pursuit of important goals (Klinger, 1977) or the development of a coherent life narrative (Kenyon, 2000; McAdams, 1993). Baumeister (1991) proposed that a feeling of meaning can be attained by first meeting needs for value, purpose, efficacy, and self-worth. Others have indicated the importance of everyday decision making and action (Maddi, 1970) or of selftranscendence (e.g., Allport, 1961; Seligman, 2002) in the creation of meaning.

Despite these differences in definitions of, and routes to, meaning in life, theorists uniformly regard meaning as crucial. Meaningful living has been directly equated with authentic living (Kenyon, 2000), and in eudaimonic theories of well-being, which focus on personal growth and psychological strengths beyond 
pleasant affect, meaning is important, whether as a critical component (Ryff \& Singer, 1998) or as a result of maximizing one's potentials (e.g., Deci \& Ryan, 2000; Maslow, 1971). Frankl (1963) argued that humans are characterized by a "will to meaning," an innate drive to find meaning and significance in their lives, and that failure to achieve meaning results in psychological distress. Research has supported this proposed link between lack of meaning and psychological distress. Having less meaning in life has been associated with greater need for therapy (Battista \& Almond, 1973), depression and anxiety (e.g., Debats, van der Lubbe, \& Wezeman, 1993), and suicidal ideation and substance abuse (e.g., Harlow, Newcomb, \& Bentler, 1986), as well as other forms of distress. Having more meaning has been positively related to work enjoyment (Bonebright, Clay, \& Ankenmann, 2000), life satisfaction (e.g., Chamberlain \& Zika, 1988b), and happiness (Debats et al., 1993), among other measures of healthy psychological functioning.

Counseling psychology has traditionally focused on positive functioning and human strengths, although more energy has been focused on "adapting deficit or pathology-oriented models to the treatment of relatively well-functioning clients than to forging, testing, and applying models of psychological health" (Lent, 2004, p. 483). Lent further argued that greater inquiry into well-being could lead to development of models of mental health that address the needs of practicing psychologists. Several counseling psychologists have commented on the importance of meaning in life and meaning-related variables to the healthy personality (Day \& Rottinghaus, 2003), psychotherapy (Gelso \& Woodhouse, 2003), health psychology (e.g., Harris \& Thoresen, 2003), and career counseling (Savickas, 2003). Meaning is one of a set of growth-related variables that are thought to provide the conditions from which happiness arises (Lent, 2004; Ryff \& Singer, 1998). Thus, meaning may contribute to the foundation of overall client happiness. Some clients may also present with a desire to become actualized and achieve a deeper sense of meaning and purpose (Lent, 2004). Further, the crises with which clients most often present offer opportunities for growth, and greater meaning or purpose in life may be one important outcome of therapy. In his monograph, Lent (2004) surveyed many of these issues and also called for efforts to purify measures of well-being constructs that overlap in item content. The present studies describe exactly such an effort.

One shortcoming in the meaning in life literature concerns measures of meaning. Most meaning research has used one of three measures: the Purpose in Life Test (PIL; Crumbaugh \& Maholick, 1964), the Life Regard Index (LRI; Battista \& Almond, 1973), or the Sense of Coherence Scale (Antonovsky, 1987), which is actually a coping disposition measure (see Sammallahti, Holi, Komulainen, \& Aalberg, 1996). Somewhat less often used are the Life Attitude Profile (Reker \& Peacock, 1981) and the Life Attitude Profile-Revised (Reker, 1992) and Ryff's (1989) Purpose in Life subscale. Many, if not all, of these scales appear to have characteristics that muddle the nomological network (Cronbach \& Meehl, 1955) of meaning, as outlined next.

Meaning in life scales have been criticized for being confounded on an item level with many of the variables they correlate with in their research applications (Dyck, 1987; Frazier, Oishi, \& Steger, 2003; Garfield, 1973; Klinger, 1977; Yalom, 1980). For instance, the PIL and the LRI contain items such as "With regard to suicide, I have thought of it seriously as a way out" and "I feel really good about my life." These items could tap any number of constructs aside from meaning, such as mood. According to Clark and Watson (1995), items assessing nearly any negative mood term will covary highly with neuroticism. Empirical findings support this idea, with disconcertingly high correlations observed between the PIL and negative affect (-.78; Zika \& Chamberlain, 1987), positive affect (.78; Zika \& Chamberlain, 1992), and life satisfaction (.71; Chamberlain \& Zika, 1988b). Other meaning measures also are highly correlated with measures of positive and negative affect (e.g., Debats et al., 1993; Zika \& Chamberlain, 1987). The investigation of potential correlates, antecedents, and consequences of meaning in life is hampered if items are included in meaning measures that tap these related constructs.

Furthermore, the factor structures of meaning measures have been somewhat problematic. Empirical testing has revealed structures different from those theorized for all of the measures of meaning that have been examined (see, e.g., Chamberlain \& Zika, 1988b; McGregor \& Little, 1998). In addition, the factor structures of often-used meaning measures such as the PIL and LRI have varied from study to study (e.g., compare Chamberlain \& Zika, 1988a, with Reker \& Cousins, 1979, and McGregor \& Little, 1998), possibly owing to the presence of multiple content domains.

Finally, given that Frankl's (1963) work, particularly Man's Search for Meaning, has been given credit for the emergence of meaning as an important variable (Wong \& Fry, 1998), it is surprising that the search for meaning in life has been all but neglected. Maddi (1970) also argued that the search for meaning is a fundamental human motivation. Crumbaugh (1977) designed the Seeking of Noetic Goals Scale to assess the "will to meaning," but criticism of that measure has been severe (e.g., Dyck, 1987; Moreland, 1985), and it has gone almost completely unused.

We sought to address these concerns by developing a new measure of meaning in life. We defined meaning in life as the sense made of, and significance felt regarding, the nature of one's being and existence. This definition represents an effort to encompass all of the major definitions of meaning and allows respondents to use their own criteria for meaning. Battista and Almond (1973) argued for a "relativistic" theory of meaning in life, in which no predetermined constraints are placed on how people may define meaning in their lives. This theory was in some ways a response to concerns that the PIL had incorporated a variety of values in the measurement of meaning, such as excitement and responsibility, that predicated having meaning on endorsing these values. Our approach was also consistent with arguments that each individual uniquely constructs his or her own life's meaning (e.g., Frankl, 1966). A similar method has been used successfully in the assessment of subjective well-being (see, e.g., Diener, Emmons, Larsen, \& Griffin, 1985; Lyubomirsky \& Lepper, 1999).

In Studies 1 and 2 we tested the item pool and assessed the structural, convergent, and discriminant validity of the Meaning in Life Questionnaire (MLQ). In Study 3 we used a multitraitmultimethod matrix design to more rigorously assess the convergent and discriminant validity of the MLQ. Study 3 also provides a comparison of the MLQ with the two most used meaning measures.

\section{Study 1a}

The purpose of Study 1 was to create and test an item pool for the construction of a measure of meaning in life. Study 1a provided 
the initial testing of items and factor structure. Study $1 \mathrm{~b}$ refined the items using confirmatory factor analyses (CFA). Efforts first were made to fully sample the content domain of meaning in life through a review of theories and existing measures of meaning in life and the search for meaning. Items were written to oversample content relevant to meaning in life (e.g., Clark \& Watson, 1995; Reise, Waller, \& Comrey, 2000) and were evaluated with regard to clarity (e.g., not asking two questions in an item; see, e.g., Dawis, 2000; Visser, Krosnick, \& Lavrakas, 2000) and content specificity (e.g., not referring to positive or negative affect; see, e.g., Clark \& Watson, 1995). Eighty-three items were initially generated. Two of the authors and two trained research assistants evaluated these items with regard to the above criteria, and 44 were retained. These 44 items were administered to a sample of undergraduate students to obtain data for factor analyses and scale revision. In addition, we examined the convergent validity of the new meaning scale by assessing correlations with measures of life satisfaction, positive affect, personality (extraversion and agreeableness), and intrinsic religiosity, and we assessed discriminant validity via correlations with measures of social desirability, extrinsic religiosity, and values. We further hypothesized negative correlations with neuroticism and depression.

\section{Method}

\section{Participants and Procedure}

The participants in this study were 151 undergraduate introductory psychology students. Their mean age was 19.8 years $(S D=3.4)$. Participants were $64 \%$ female; most were Caucasian (76\%), followed by Asian (10\%), African American (3\%), Native American (3\%), Asian American (2\%), and Hispanic (1\%), with 5\% of participants endorsing "other." Participants were administered the 44 items that met the above criteria and completed additional self-report inventories, as reported below.

\section{Measures}

In addition to assessment of demographic variables, several measures were distributed with the 44 MLQ items to a subset of the participants to obtain evidence of convergent and discriminant validity for the MLQ as a measure of the presence of meaning in life as scale construction proceeded (see Clark \& Watson, 1995). All of the measures used, except for the values measure, were selected because of demonstrated validity and reliability in previous studies. Results of convergent and discriminant validity analyses are presented at the end of Study $1 b$.

The Satisfaction With Life Scale (SWLS; Diener et al., 1985) is a widely used and well-validated measure of life satisfaction. Satisfaction with life represents the cognitive aspect of subjective well-being (Lucas, Diener, \& Suh, 1996). Respondents use a 7-point scale ranging from strongly disagree to strongly agree to rate the scale's five items. The SWLS has demonstrated good reliability, as well as convergent and discriminant validity (for a review, see Pavot \& Diener, 1993). Internal consistency in the present sample was good $(\alpha=.84)$.

The Long-Term Affect Scale (LTAS; Diener, Smith, \& Fujita, 1995) was used to assess the affective component of subjective well-being. The LTAS consists of 24 affective adjectives that make up two positive (Joy $[\alpha=.75]$, Love $[\alpha=.82]$ ) and four negative (Shame $[\alpha=.82]$, Fear $[\alpha=$ $.81]$, Anger $[\alpha=.83]$, and Sadness $[\alpha=.86])$ affect scales. Adjectives are rated on 7-point scales, on which participants indicate how often they felt each emotion in the past month, from always to never. Diener et al. have established the internal consistency and convergent and discriminant validity of the LTAS.
Extraversion $(\alpha=.76)$, conscientiousness $(\alpha=.74)$, openness ( $\alpha=$ $.81)$, agreeableness $(\alpha=.87)$, and neuroticism $(\alpha=.85)$ were measured using eight items each from Saucier's (1994) Mini-Markers. Saucier presented validity information in the form of principal-components analysis that mapped onto the pervasive five-factor theory of personality.

Participants also completed the Brief Symptom Inventory (BSI; Derogatis \& Spencer, 1992) Depression subscale. The BSI is a short version of the Symptom Check List 90, which assesses self-reports of psychological distress $(\alpha=.84)$. Participants indicated the degree to which they experienced six depression symptoms (e.g., feeling blue) over the past month. Responses were made on a 5-point scale $(0=$ not at all to $4=$ extremely). Derogatis has presented research supporting the reliability and validity of the BSI as a measure of psychological distress.

The 14-item Intrinsic/Extrinsic Religiosity Scale (Gorsuch \& McPherson, 1989) was used to assess the extent to which individuals engage in religious commitments for the sake of faith itself (Intrinsic Religiosity, $\alpha=$ .71) versus using religion as an instrumental means to other ends (Extrinsic Religiosity, $\alpha=.78$ ). Eight items assess intrinsic religiosity on a scale from 1 (strongly disagree) to 5 (strongly agree), and six items assess extrinsic religiosity on the same scale. Consistent with other researchers interested in avoiding the potential Christian bias in some items (e.g. Bouchard, McGue, Lykken, \& Tellegen, 1999), the term "church" was replaced with "religious services." The Intrinsic/Extrinsic Religiosity Scale has been recommended as the best available instrument for research in religion (Van Wicklin, 1990).

Participants completed the 33-item Marlowe-Crowne Social Desirability Scale (Crowne \& Marlowe, 1960), a widely used inventory that assesses the need to obtain social approval using a series of statements concerning socially desirable opinions or behaviors that most people cannot truthfully claim to adhere to at all times, as well as 14 statements of socially undesirable opinions or behaviors that have been true for most people at least some of the time $(\alpha=.80)$. Those who respond true to many of the socially desirable and false to many of the socially undesirable statements have a high need for social approval that is presumed to affect their responses to psychological measures.

Finally, values were measured by having participants rank in order of importance descriptors of the 10 value types (security, power, achievement, hedonism, stimulation, self-direction, universalism, benevolence, tradition, and conformity) proposed by Schwartz and Sagiv (1995). Thus, analyses were of the relation between scores on MLQ scales and the relative importance of each value individually, rather than with a full scale score. Schwartz's values scale has received considerable attention, and its psychometric properties have been supported in numerous studies. A pairwise comparison form of these 10 values has been used successfully in the past (i.e., Oishi, Diener, Suh, \& Lucas, 1999).

\section{Results and Discussion}

The correlation matrix of the 44 items was first subjected to a principal-axis factor analysis (PFA) with oblique, direct oblimin rotation (deltas $=0$ ). PFA was chosen over principal-components analysis because principal-components analysis introduces more spurious common variance into solutions (Comrey, 1988), assumes perfect measurement (Finch \& West, 1997), and is more appropriate for data reduction than latent variable identification (Floyd \& Widaman, 1995). PFA will generally produce results similar to those of maximum likelihood extraction (which was the case in these studies when duplicate analyses were performed) and is less sensitive to nonnormality (Finch \& West, 1997).

Scree-plot analysis indicated that as many as six factors could be present in the data, with eigenvalues of 11.63, 8.07, 2.03, 1.82, 1.54 , and 1.27 , but strongly suggested the existence of two dominant factors. The overall aim of scale development is to create 
indices of theoretically interesting and interpretable constructs. Therefore, we examined the rotated pattern matrix of the initial item pool with an eye for whether the factors focused on important meaning in life-related constructs or whether they appeared to focus on extraneous content. The first factor clearly tapped the presence of meaning or purpose in a person's life. The second factor captured the search for meaning. These two factors were of substantial theoretical interest given previous research on the presence of meaning in people's lives and the emphasis on the search for meaning (e.g., Frankl, 1963; Maddi, 1970). Factors 3, 4, and 5 appeared either to be redundant with the presence of meaning factor, center around skepticism regarding the existence of an "ultimate meaning of life," or assess goal directedness. The sixth factor consisted of one item that loaded more highly on the redundant meaning in life factor.

Next, the two principal factors described above (labeled Presence and Search) were extracted from the 44 items and obliquely rotated. To create independence between the scales, we used a criterion of factor loadings above .60 on the intended factor and below .20 on the other factor for item retention (see Watson, Clark, $\&$ Tellegen, 1988). Seventeen items met this criterion (9 on the Presence subscale, 8 on the Search subscale). These items were tested and further refined using CFA in Study $1 \mathrm{~b}$.

\section{Study $1 \mathrm{~b}$}

We used CFA to further refine the item pool for assessing the Presence and Search factors. The modification indices and empirical tests of model fit available in CFA provide excellent information for refining and revising scales (Floyd \& Widaman, 1995). However, as modification indices from the CFAs were used to revise the scales, replication in independent samples is especially important (Floyd \& Widaman, 1995; Reise et al., 2000). This replication was done in Studies 2 and 3.

\section{Method}

Participants were recruited from undergraduate introductory psychology classes. The 154 participants were on average 21.8 years of age $(S D=3.9)$ and mostly female (70\%); most were Caucasian (79\%), followed by Asian (9\%), Native American (4\%), African American (3\%), Asian American (2\%), and Hispanic (1\%), with $2 \%$ endorsing "other."

The 17 items loading on the Presence and Search factors retained in Study 1a were subjected to CFA, using the structural equation modeling program AMOS 4.01 (Arbuckle, 1999).

\section{Results and Discussion}

We assessed goodness of fit with a variety of fit indices, as is widely recommended (scores below .90 indicate acceptable fit, per Finch \& West, 1997, except for the root-mean-square error of approximation [RMSEA], on which values below .10 indicate adequate fit; Browne \& Cudeck, 1993). These 17 items did not achieve acceptable fit with the two-factor model proposed, $\chi^{2}(118$, $N=154)=353.87, p<.0001$ (goodness-of-fit index $=.77$; adjusted goodness-of-fit index $=.71$; normed fit index $=.79$; Tucker-Lewis index $=.83$; comparative fit index $=.85$; RMSEA $=.11$ ). Three items (two from the Presence factor, one from the Search factor) were first eliminated because they reduced model fit (modification index $>12.0$ ) and had low factor loadings (less than .50), leaving a 14-item scale with marginally acceptable fit indices. We then conducted a CFA with the remaining 14 items. Modification indices indicated that allowing a number of residuals to covary and eliminating additional items from each scale would improve model fit. Decisions regarding whether to follow the modification indices were based on theoretical considerations of item and scale content. We did not allow residuals to covary, because there is no theoretical reason to assume associations among residuals. However, we did eliminate items if they had low factor loadings $(<.60)$ and if modification indices suggested their elimination would improve model fit, whether because of substantial covariance with the unintended latent factor or with other items. Negatively worded items were selected for retention over more highly loading positively worded items in the hopes of ameliorating response sets (see the Appendix for the final, 10-item MLQ).

Fitting items to scales is more difficult than fitting scales to latent constructs given the greater error variance in single-item scale scores and given that models estimating fewer parameters are generally easier to support (Floyd \& Widaman, 1995). Thus, there is a tension between achieving the best model fit and including a sufficient number of items to satisfy traditional psychometric concerns, such as internal consistency (Clark \& Watson, 1995). The model that appeared to best balance concerns regarding model fit and internal consistency comprised five items per scale (see the Appendix). The best way to determine the quality of model fit is to look for agreement and consistency across a number of fit indices (Dilalla, 2000; Ullman, 2001). Fit indices for the 10-item model are presented in Table 1 and overall indicated a good fit. The Presence and Search factors were slightly intercorrelated $(r=$ $-.19)$. In addition, internal consistency was good for both the

Table 1

Summary of Fit Indices for Confirmatory Factor Analyses in Studies 1-3

\begin{tabular}{ccccccccccc}
\hline Study & $N$ & $\chi^{2}$ & GFI & AGFI & NFI & TLI & CFI & IFI & RMSEA & $\alpha(\mathrm{P} / \mathrm{S})$ \\
\hline $1 \mathrm{~b}$ & 153 & $57.68^{* *}$ & 0.93 & 0.89 & 0.93 & 0.96 & 0.97 & 0.97 & 0.07 & $.86 / .87$ \\
2 & 279 & $56.04 * *$ & 0.97 & 0.96 & 0.97 & 0.98 & 0.99 & 0.99 & 0.04 & $.86 / .86$ \\
3 & 402 & $149.59^{* * * *}$ & 0.93 & 0.89 & 0.92 & 0.91 & 0.93 & 0.93 & 0.09 & $.82 / .87$ \\
\hline
\end{tabular}

Note. $\mathrm{CFI}=$ comparative fit index; IFI $=$ incremental fit index; RMSEA $=$ root-mean-square error of approximation; GFI = goodness-of-fit index; AGFI = adjusted goodness-of-fit index; NFI = normed fit index; TLI $=$ Tucker-Lewis index. $(\mathrm{P} / \mathrm{S})=$ Presence/Search subscales

$* * p<.01 . \quad * * * * p<.001$. 
Presence (.86) and Search (.87) subscales. A PFA was performed to calculate item cross-loadings, which are not estimated in CFA. All items loaded more highly on the intended factor (.70 to .84) than on the other (-.10 to .13). Additional item statistics are provided for the final 10 items in Table 2 .

\section{Descriptive Statistics}

Mean scores were $23.5(S D=6.6)$ and $23.1(S D=6.6)$ on the MLQ Presence (MLQ-P) and Search (MLQ-S) subscales, respectively. Scores were slightly above but close to the midpoint of the scale (20). The shape of the distributions approximated normality, and scores were variable, as demonstrated by their standard deviations.

\section{Relations With Demographics}

Scores on the MLQ Presence and Search subscales did not differ across gender, race, or religion. Neither subscale was related to grade point average. However, Presence had a small positive correlation with age $(r=.17, p<.05)$.

\section{Convergent Validity}

Correlations among the final MLQ subscales and other variables were calculated and are presented in Table 3. As predicted, Presence positively correlated with life satisfaction, positive emotions, intrinsic religiosity, extraversion, and agreeableness and negatively correlated with depression, negative emotions, and neuroticism. The one unexpected finding was the positive correlation between Presence and conscientiousness, although this is similar to findings regarding psychological well-being, which includes purpose in life (Keyes, Shmotkin, \& Ryff, 2002). Although the Search subscale overall seemed unrelated to these constructs, it was significantly positively correlated with neuroticism, depression, and several negative emotions, consistent with Frankl (1963, 1965).

Table 2

Descriptive Statistics for Final Item Selection, Study $1 b$

\begin{tabular}{cccc}
\hline & & & Item \\
Subscale & $\begin{array}{c}\text { Item means } \\
(S D)\end{array}$ & $\begin{array}{c}\text { Corrected } \\
\text { item-scale } r\end{array}$ & $\begin{array}{c}\text { cored } \\
\text { multiple } \\
\text { correlations }\end{array}$ \\
\hline Presence & & & \\
MLQ 1 & $4.1(1.7)$ & .72 & .53 \\
MLQ 4 & $4.7(1.5)$ & .71 & .52 \\
MLQ 5 & $5.1(1.3)$ & .66 & .44 \\
MLQ 6 & $4.4(1.6)$ & .67 & .46 \\
MLQ 9(r) & $5.6(1.5)$ & .65 & .44 \\
Search & & & .50 \\
MLQ 2 & $4.3(1.6)$ & .63 & .42 \\
MLQ 3 & $5.0(1.4)$ & .70 & .50 \\
MLQ 7 & $4.4(1.5)$ & .70 & .61 \\
MLQ 8 & $4.8(1.5)$ & .77 & \\
MLQ 10 & $4.5(1.7)$ & & .60 \\
\hline
\end{tabular}

Note. $\quad N=154$. MLQ $=$ Meaning in Life Questionnaire. (r) indicates reverse-scored item.
Table 3

Correlations Between MLQ Subscales Presence and Search and Other Well-Being Measures in Studies $1 a$ and $1 b$

\begin{tabular}{lcc}
\hline & Presence & Search \\
\hline Presence $^{\mathrm{a}}$ & $(.86)$ & \\
Search $^{\mathrm{a}}$ & -.09 & $.87)$ \\
Life Satisfaction $^{\mathrm{b}}$ & $.46^{* * *}$ & -.12 \\
Love $^{\mathrm{b}}$ & $.40^{* * *}$ & -.04 \\
Joy $^{\mathrm{b}}$ & $.49^{* * *}$ & -.09 \\
Fear $^{\mathrm{b}}$ & $-.20^{*}$ & $.25 * * *$ \\
Anger $^{\mathrm{b}}$ & $-.17^{*}$ & .14 \\
Shame $^{\mathrm{b}}$ & $-.20^{*}$ & $.19^{*}$ \\
Sadness $^{\mathrm{b}}$ & $-.35^{* * *}$ & $.26^{* * *}$ \\
Neuroticism $^{\mathrm{b}}$ & $-.23^{* *}$ & $.20^{*}$ \\
Extraversion $^{\mathrm{b}}$ & $.28^{* * *}$ & -.09 \\
Openness $^{\mathrm{b}}$ & .13 & .09 \\
Conscientiousness $^{\mathrm{b}}$ & $.17^{*}$ & .03 \\
Agreeableness $^{\mathrm{b}}$ & $.23^{* *}$ & .03 \\
Depression $^{\mathrm{c}}$ & $-.48^{* * *}$ & $.36^{* * *}$ \\
Intrinsic Religiosity $^{\mathrm{b}}$ & $.30^{* * *}$ & .11 \\
Extrinsic Religiosity $^{\mathrm{b}}$ & .15 & .12 \\
Social Desirability $^{\mathrm{d}}$ & -.08 & .02 \\
Power $^{\mathrm{b}}$ & .04 & .02 \\
Achievement $^{\mathrm{b}}$ & .02 & .11 \\
Hedonism $^{\mathrm{b}}$ & -.01 & -.12 \\
Stimulation $^{\mathrm{b}}$ & .07 & -.00 \\
Self-Direction $^{\mathrm{b}}$ & -.01 & .15 \\
Universalism $^{\mathrm{b}}$ & .03 & .13 \\
Benevolence $^{\mathrm{b}}$ & .06 & -.04 \\
Tradition $^{\mathrm{b}}$ & .14 & -.09 \\
Conformity $^{\mathrm{b}}$ & -.06 & -.12 \\
Security $^{\mathrm{b}}$ & .13 & -.02 \\
\hline & & \\
\hline
\end{tabular}

Note. Sample sizes differ depending on the correlation because not everybody completed all measures. MLQ = Meaning in Life Questionnaire. Numbers in parentheses are alpha coefficients.

${ }^{\mathrm{a}} n=304 .{ }^{\mathrm{b}} n=151 .{ }^{\mathrm{c}} n=120 .{ }^{\mathrm{d}} n=271$

$* p<.05 . \quad * * p<.01 . \quad * * * p<.005$.

\section{Discriminant Validity}

Consistent with the relativistic value-free approach used in scale development, scores on the MLQ subscales were uncorrelated with the value rankings. The MLQ subscales were also unrelated to social desirability. The nonsignificant relation between meaning and extrinsic religiosity is evidence of discriminant validity, because extrinsic religiosity describes the component of religiousness that is divorced from spiritual meaning.

\section{Summary of Studies $1 a$ and $1 b$}

In sum, in Study 1a, exploratory factor analysis identified two independent factors, labeled Presence of Meaning and Search for Meaning. In Study 1b, a CFA indicated that the best model was one in which each factor was measured with five items. These two subscales were also shown to be internally consistent. In addition, theoretically expected convergence with and discrimination from other measures were documented. To assess the robustness of the factor structure, we sought replication in an independent sample.

Study 2

\section{Method}

Participants were 400 students recruited from introductory psychology classes, mostly women (59\%). Most were Caucasian (77\%), followed by 
Asian or Asian American (10\%), and African American (4\%), with 1\% each for Native American and Hispanic. Their mean age was 19.7 years $(S D=3.0)$. Participants completed a short survey packet including the 10-item MLQ, as well as the last 4 MLQ items to be eliminated in Study $1 \mathrm{~b}$, to allow testing of alternate factor structures in the event of poor model fit.

\section{Results and Discussion}

All analyses were performed on the 10-item MLQ. Mean scores were $23.8(S D=5.9)$ and $23.4(S D=6.3)$ on the Presence and Search subscales, respectively, and the scales were internally consistent (see Table 1 for alphas). The same factorial model was tested in this study as in Study 1b with CFA using AMOS 4.01 (Arbuckle, 1999). The CFA path estimate indicated a stronger relation between Presence and Search than observed in Study 1 $(\beta=-.28)$. Factor loadings were robust (between .65 and .83 on their intended factors), and fit indices indicated a good fit of the model to the data (see Table 1). This study provides a replication of the two-factor structure of the MLQ.

\section{Summary of Studies 1 and 2}

In contrast to previous meaning in life scales, the MLQ has a robust factor structure, replicated by CFA in an independent sample. The Presence of Meaning subscale measures the subjective sense that one's life is meaningful, whereas Search for Meaning measures the drive and orientation toward finding meaning in one's life. Both subscales have demonstrated good internal consistency $(\alpha \mathrm{s}=.86-.88)$. Scale construction was geared toward creating somewhat orthogonal factors, selecting items that loaded highly on the intended factor and minimally on the other factor. This enables the assessment of these two distinct constructs, the search for meaning and the presence of meaning.

The relative independence of these two subscales creates an apparent conceptual paradox, however. Why would someone report searching for something they already have? Why wouldn't someone search for meaning if he or she reported not having any? Exemplars of individuals who continued to search for greater meaning in their lives while already living lives of deep purpose are readily available (e.g., Gandhi). Another line of thinking suggests that if those who derive meaning from more sources in their lives fare better (Baumeister, 1991), then those who report having meaning might still continue to search for additional sources of meaning. Alternatively, the search for meaning could be a desire for a deeper or more gratifying understanding of what makes one's life meaningful. Finally, it could also be the case that the elements that give meaning to a person's life fluctuate over time. For instance, one could derive a great deal of meaning from training for a first marathon but find that upon its conclusion, one has a desire to find something else to make life feel meaningful, without necessarily experiencing meaninglessness.

The Presence and Search subscales correlated generally as expected with other well-being and psychological variables, with the magnitude of correlations in Study $1 \mathrm{~b}$ generally indicating that Presence shares less than $25 \%$ of its variance with other measures. This is in contrast to other meaning measures, which often appear to share more than $50 \%$ of their variance with other measures (e.g., Zika \& Chamberlain, 1987). Because one of the criticisms of meaning measures is that they are confounded with other con- structs (e.g., Dyck, 1987), a more formal test of the discriminant validity of the MLQ was desired. Of particular importance was a comparative analysis of the relations among the MLQ scales, other meaning in life scales, and other well-being variables.

\section{Study 3}

The purposes of this study were (a) to further establish the convergent and discriminant validity of the MLQ subscales and (b) to compare the discriminant validity of meaning measures (i.e., MLQ Presence, PIL, and LRI). We used a multitrait-multimethod matrix (MTMM) design, which allows for a comprehensive analysis of convergent and discriminant validity (Campbell \& Fiske, 1959). Convergent validity is demonstrated by significant correlations between different methods of measuring the same trait (monotrait-heteromethod). Discriminant validity requires a lengthier set of comparisons, all of which essentially demonstrate higher correlations among methods of assessing the same trait as compared with those measuring different traits (either heterotraitmonomethod or heterotrait-heteromethod). The two methods were participant's self-report and informant report. Participants completed the MLQ and a variety of other meaning and well-being measures at two time points (1 month apart). Informant reports of all the measures were obtained once, between Times 1 and 2 .

Convergent validity in an MTMM study is established when different methods of measuring the same trait are significantly related. Thus, self-reports on the Presence and Search subscales were expected to be significantly positively correlated with informant reports on those same subscales. Because the Presence subscale was designed to measure the same construct as the LRI and the PIL, significant correlations between self- and informant reports on the MLQ-P and the two other meaning measures would indicate convergent validity as well. Very large $(>.70)$ relations were expected among self-reports of the MLQ-P, LRI, and PIL.

Discriminant validity would be established if different methods of assessing the presence and search for meaning were more highly related to each other than to methods of assessing different traits. Evidence of discriminant validity could be obtained by including measures of a theoretically unrelated trait, such as social desirability, in an MTMM. Including measures of related but different traits would yield a more robust test. Thus, measures of life satisfaction, self-esteem, and optimism, which overlap theoretically with meaning in life, were included. For example, one may be inclined to endorse a variety of well-being variables, potentially including meaning, if one generally regards oneself highly. Conversely, if one feels dissatisfied with one's life, one may be inclined to search for alternatives, including a search for meaning in life. The MLQ subscales were expected to correlate with other well-being scales, in accordance with previous research using these subscales (i.e., small to medium effect sizes for the MLQ-S and medium to large effect sizes for the MLQ-P). Correlations of these sizes would indicate significant relations but would not suggest confounding with well-being variables. Also, the Search subscale was expected to be uncorrelated, or to exhibit small effect sizes, with the meaning measures, supporting its relative independence from meaning in life. In addition, the MLQ-P subscale was expected to correlate more highly with other meaning measures than with well-being measures. These findings would provide strong support for the 
discriminant validity of the MLQ-P as a measure of meaning in life, as opposed to other forms of well-being.

Because of previous work highlighting possible confounding with other constructs in the two most commonly used measures of meaning in life, the second aim of this study was to compare the discriminant validity of the MLQ-P, the PIL, and the LRI. The correlations between the PIL and the LRI and other well-being measures were expected to occasionally exceed the correlations between self-report and informant report on these two scales. This would indicate a lack of adequate discriminant validity for these two scales.

\section{Method}

\section{Participants and Procedure}

Participants were recruited from a large university and a large community college from the Minneapolis metropolitan area. Seventy participants (mean age $=21.1, S D=5.2$ ) completed both the Time 1 and Time 2 packets and returned informant packets. Participants were mostly female (63\%) and Caucasian (75\%), followed by Asian (8\%), Asian American (4\%), African American (3\%), and Hispanic (3\%), with $1 \%$ reporting Native American and 6\% reporting "other." Most participants were Protestant (34\%) or Catholic (30\%; all other religions less than 6\%). All target participants completed a packet of surveys at two times, separated by 1 month, in large groups. Participants were asked to obtain informant reports from three or four people who knew them well (e.g., friends, parents, or siblings). Informants $(n=252)$ were somewhat older and more varied in age than target participants (mean age $=26.5, S D=$ 12.2). They were mostly undergraduate students (63\%) and female $(63 \%)$; most were Caucasian (82\%), followed by Asian (6\%), Asian American (4\%), and African American (2\%), with 1\% each reporting Native American and Hispanic, and $4 \%$ reporting "other."

Most informants were Catholic (39\%) or Protestant (31\%; all other religions less than $4 \%$ ). Informants were instructed to respond in the manner they thought their friend or family member would respond if they were filling out the survey about themselves. Informants were asked to inscribe the initials of the target participant several times during the instructions and again prior to completing each scale. Informants filled out survey packets on their own time. In addition to the packet of surveys they were to complete about the study targets, informants were given self-report versions of the MLQ.

Participant Time 1 and informant self-reported scores on the MLQ were combined to provide a sample for the replication of the two-factor structure. The average age of the combined sample (targets and informants; $61 \%$ female) was 24.4 years $(S D=10.4)$. Thus, the combined sample $(N=401)$ was older and more diversely aged than the samples in Studies 1a, 1b, and 2. Only $47 \%$ of the participants completed both survey packets and returned at least three informant reports (70 out of 149 who completed the Time 1 survey). Those who returned at least three reports did not differ from those who did not in gender, age, race, religious affiliation, or year in school.

\section{Measures}

Participants indicated their age, gender, religion, and grade point average and also completed the MLQ and SWLS (Diener et al., 1985), which were previously described. In addition, survey packets included the following measures.

The LRI (Battista \& Almond, 1973) is a 28 -item scale that assesses positive life regard, defined as the extent to which a person has a valued life framework, or meaning structure, and feels that this framework is being fulfilled. The LRI has two 14-item subscales that purport to measure the framework and fulfillment aspects of life regard, although the difficulty of obtaining appropriate factorial fit has led to the recommendation that the scale be used unidimensionally (Harris \& Standard, 2001). The LRI has consistently demonstrated excellent internal consistency (e.g., Zika \&
Chamberlain, 1992). Reliability data for this and all other scales used in Study 3 are reported in Table 4 .

The 20-item PIL (Crumbaugh \& Maholick, 1964) is the most widely used meaning in life scale, despite the concerns described previously regarding confounding with other variables and problems with its factorial structure. Nonetheless, the scale has generally demonstrated good convergent validity with measures of well-being and distress, as well as good internal consistency (e.g., Zika \& Chamberlain, 1992). The PIL provides participants with unique anchors for each item, some of which are bipolar, some of which are unipolar, and some of which provide an indeterminate continuum (i.e., "If I could choose, I would . . . " "prefer never to have been born" through "live nine more lives just like this one").

Participants also completed the Life Orientation Test (LOT; Scheier \& Carver, 1985), a commonly used 12-item measure of optimism. Respondents indicated the extent to which they agreed or disagreed with 4 positively worded, 4 negatively worded, and 4 filler items. The LOT has demonstrated good validity and reliability (see Scheier \& Carver, 1985).

Finally, packets included the Rosenberg Self-Esteem Test (RSET; Rosenberg, 1965), a widely accepted 10-item measure assessing the positivity of self-regard on a 4-point scale ranging from strongly disagree to strongly agree. The RSET has demonstrated reliability and validity in a large number of studies (e.g., Lucas et al., 1996).

\section{Results and Discussion}

Mean scores for target participants at Time 1 on the Presence and Search subscales were $24.0(S D=5.6)$ and $22.5(S D=6.2)$, respectively. University students did not differ from community college students, and participants who dropped out after Time 1 did not differ on any of the meaning or well-being variables (all $p$ s $>.15$ ). Scores did not differ across gender, race, or year in school. Presence scores differed across religion, $F(7,133)=2.39$, $p<.05$, with participants endorsing "other" religions scoring higher than Protestants, Catholics, atheists, or agnostics, and agnostics scoring lower than Muslims. Search was related to grade point average $(r=.21, p<.05)$, and as in Study 1, Presence was related to age $(r=.20, p<.05)$. This latter relation is in concordance with other findings (e.g., Reker \& Fry, 2003). The mean scores for informants' self-reports of the MLQ were 24.8 $(S D=5.6)$ for Presence and $21.8(S D=6.9)$ for Search.

\section{CFA of MLQ Structure in a Replication Sample}

CFA on the combined sample was performed using AMOS 4.01 (Arbuckle, 1999). Factor loadings were all high (.55 to .84). Fit indices were acceptable (see Table 1). The marginal RMSEA and adjusted goodness-of-fit index indicate a lack of full parsimony, suggesting that fewer items might reflect the factor structure with similar accuracy (Dilalla, 2000; Finch \& West, 1997). However, as stated above, five items per scale was desired to maintain internal consistency. Both Presence $(\alpha=.82)$ and Search $(\alpha=.87)$ displayed good reliability in the aggregate sample.

\section{Reliability for the MLQ and Other Meaning Measures}

The alpha coefficients for the target self-reports on the MLQ-P and MLQ-S were .81 and .84 during Time 1, respectively, and .86 and .92 during Time 2, representing good internal consistency. One-month test-retest stability coefficients were good (.70 for the MLQ-P, .73 for the MLQ-S). The PIL (.86) and LRI (.87) also showed good temporal stability and good internal consistency (.88 and .93 , respectively). 
Table 4

Multitrait-Multimethod Correlation Matrix of Meaning in Life and Well-Being Measures in Study 4

\begin{tabular}{|c|c|c|c|c|c|c|c|c|c|c|c|c|c|c|c|c|c|c|c|c|c|}
\hline & 1 & 2 & 3 & 4 & 5 & 6 & 7 & 8 & 9 & 10 & 11 & 12 & 13 & 14 & 15 & 16 & 17 & 18 & 19 & 20 & 21 \\
\hline 1. MLQ-P & .814 & & & & & & & & & & & & & & & & & & & & \\
\hline 2. PIL & .606 & .875 & & & & & & & & & & & & & & & & & & & \\
\hline 3. LRI & .659 & .804 & .930 & & & & & & & & & & & & & & & & & & \\
\hline 4. SWL & .411 & .686 & .600 & .855 & & & & & & & & & & & & & & & & & \\
\hline 5. EST & .372 & .643 & .697 & .553 & .836 & & & & & & & & & & & & & & & & \\
\hline 6. LOT & .370 & .680 & .664 & .502 & .607 & .826 & & & & & & & & & & & & & & & \\
\hline 7. MLQ-S & -.241 & $-.179-$ & $-.302-$ & -.239 & $-.305-$ & -.174 & .840 & & & & & & & & & & & & & & \\
\hline 8. fMLQ-P & .283 & .243 & .281 & .152 & .197 & .278 & -.214 & .757 & & & & & & & & & & & & & \\
\hline 9. fPIL & .267 & .422 & .429 & .391 & .390 & .364 & -.227 & .298 & .869 & & & & & & & & & & & & \\
\hline 10. fLRI & .305 & .413 & .467 & .354 & .335 & .416 & -.311 & .383 & .427 & .913 & & & & & & & & & & & \\
\hline 11. fSWL & .187 & .384 & .386 & .448 & .320 & .295 & -.253 & .251 & .457 & .359 & .821 & & & & & & & & & & \\
\hline 12. fEST & .184 & .335 & .381 & .342 & .369 & .334 & -.235 & .263 & .403 & .417 & .371 & .860 & & & & & & & & & \\
\hline 13. fLOT & .148 & .241 & .291 & .258 & .236 & .360 & -.206 & .242 & .320 & .379 & .294 & .346 & .841 & & & & & & & & \\
\hline 14. fMLQ-S & -.115 & $-.134-$ & $-.180-$ & $-.202-$ & $-.189-$ & -.035 & .308 & $-.135-$ & $-.097-$ & -.135 & -.215 & $-.188-$ & -.123 & .857 & & & & & & & \\
\hline 15. 2MLQ-P & 699 & .597 & .667 & .484 & .396 & .491 & -.316 & .390 & .296 & .464 & .279 & .223 & .251 & -.140 & .855 & & & & & & \\
\hline 16. 2PIL & .582 & .861 & .780 & .647 & .592 & .673 & -.205 & .277 & .445 & .489 & .439 & .356 & .344 & -.047 & .708 & .885 & & & & & \\
\hline 17. 2LRI & .597 & .781 & .866 & .596 & .651 & .708 & -.229 & .329 & .439 & .527 & .414 & .366 & .381 & -.095 & .742 & .862 & .941 & & & & \\
\hline 18. $2 \mathrm{SWL}$ & .375 & .609 & .590 & .798 & .454 & .508 & -.343 & .226 & .351 & .423 & .421 & .311 & .347 & -.129 & .558 & .746 & .653 & .859 & & & \\
\hline 19. $2 \mathrm{EST}$ & .348 & .648 & .609 & .542 & .819 & .556 & -.213 & .130 & .326 & .302 & .327 & .361 & .242 & -.091 & .380 & .693 & .672 & .560 & .853 & & \\
\hline 20. $2 \mathrm{LOT}$ & .406 & .619 & .692 & .496 & .590 & .814 & -.144 & .258 & .357 & .446 & .332 & .340 & .418 & -.074 & .568 & .742 & .790 & .580 & .617 & .883 & \\
\hline 21. 2MLQ-S & -.340 & $-.251-$ & $-.339-$ & $-.375-$ & $-.326-$ & -.261 & .725 & -.223 & $-.224-$ & -.336 & -.264 & $-.294-$ & -.304 & .350 & -.296 & -.209 & -.303 & -.276 & $-.218-$ & -.146 & .915 \\
\hline
\end{tabular}

Note. Correlations are based on 70 participants (the number of participants who completed both Time 1 and 2 reports and returned at least three informant packets). Correlations above .198 are significant at $p<.05$. MLQ $=$ Meaning in Life Questionnaire. Time 1 target self-reports are MLQ-P $=$ MLQ-Presence; PIL = Purpose in Life Test; LRI = Life Regard Index; SWL = Satisfaction with Life Scale; EST = Rosenberg Self-Esteem Inventory; LOT = Life Orientation Test (optimism); and MLQ-S = MLQ-Search. Informant Reports are fMLQ-P; fPIL; fLRI; fSWL; fEST; fLOT; and fMLQ-S $\mathrm{f}$ indicates friend. Time 2 target self-reports are 2MLQ-P; 2PIL; 2LRI; 2SWL; 2EST; 2LOT; and 2MLQ-S. 2 indicates Time 2. Bold italics indicate scores on same measures using different methods or at retest. Italics indicate alpha coefficients and are on the diagonal.

Consistent with Lucas et al. (1996), all other well-being measures (life satisfaction, optimism, self-esteem) also showed good test-retest reliability and internal consistency (see Table 4).

\section{Convergent and Discriminant Validity Analysis}

Bivariate correlation coefficients were computed between all concurrently and longitudinally collected self-report measures. To compute correlation values for target self-reports and informant reports at Time 1 and Time 2, the correlations between informant and self-report ratings were first computed for each informant separately. Only data from participants with three or more informant reports were used to calculate convergence between targets and informants. Among the 70 participants who turned in three or more informant packets, 14 turned in four. Three packets were randomly selected for each of these 14 participants. Thus, target self-report scores were correlated with three informant scores for each participant. The average of these three correlation coefficients was then entered into the matrix. Average coefficients representing informant-informant correlations were calculated by taking the average of nine coefficients ( 3 informants $\times 3$ informants). Averaged correlations provide a more accurate estimate of relationships than creating "composite informants" (e.g., Sandvik, Diener, \& Siedlitz, 1993) because the aggregation of multiple informant scores can inflate reported relationships, whereas averaging the correlations better represents the actual observed relationships
(Malloy, Albright, Kenny, Agatstein, \& Winquist, 1997). The full correlation matrix is shown in Table 4.

We performed several of the typical comparisons described by Campbell and Fiske (1959). However, two specific aspects of this MTMM caused us to alter our comparison strategy. The first was the inclusion of two other measures of meaning in life, as discussed previously, which enabled us to test the convergent validity of the MLQ-P using the LRI and PIL as additional measures of meaning in life. The second aspect was that the Time 2 administration was not a completely independent method, because it used the same self-report format as Time 1 . Thus, we treated the Time 1 and Time 2 reports as the same method. Because of this, we compared the validity diagonals (the convergence of scores on the same measure across methods, or monotrait-heteromethod values; Campbell \& Fiske, 1959) at both Time 1 and Time 2 with all of the correlations between self- and informant reports (i.e., all of the heterotrait-heteromethod and heterotrait-monomethod values for the MLQ subscales). Thus, instead of comparing self- and informant report correlations at Time 1 with informant reports and Time 1 reports only, we also compared them with Time 2 reports. This strategy led to more comparisons, but in addition, it both provided a most rigorous test of discriminant validity and seemed a more accurate reflection of the high degree of overlap between the Time 1 self-report and the retest 1 month later. We first present evidence for the MLQ-P, followed by the MLQ-S. 


\section{Convergent and Discriminant Validity for the $M L Q-P$}

Convergent validity between target and informant reports on the $M L Q-P$. To establish convergent validity, self-reports should be correlated with informant reports. Both the Time 1 (.28) and Time 2 (.39) monotrait-heteromethod correlations between self- and informant reports on the MLQ-P were significant.

Convergent validity with other meaning measures. Because they purport to measure the same construct, the MLQ-P should be significantly correlated with the LRI and PIL. All eight self-report correlations (i.e., two correlations between Time 1 MLQ-P and Time 1 PIL and LRI, two between Time 1 MLQ-P and Time 2 meaning measures, two between Time 2 MLQ-P and Time 2 measures, and two between Time 2 MLQ-P and Time 1 measures) between the MLQ-P and the PIL and LRI were significant and ranged from .58 to .74 . These correlations were higher than Cohen's (1992) conventions for large effect sizes. Correlations among self- and informant reports should also be significant for these measures. All four heteromethod correlations between the MLQ-P and the other meaning measures were significant and ranged from .29 to .38 . Thus, these two tests provide evidence of the convergent validity of the MLQ-P.

Discriminant validity of the $M L Q-P$. Self-report scores on the MLQ-P were expected to correlate more highly with self-reports on other meaning measures than with self-reports on well-being measures (i.e., self-esteem, life satisfaction, optimism). The testretest coefficient for the MLQ-P was .70, and the average correlation of the MLQ-P with other meaning measures was .65. These correlations were in all cases higher than the self-report correlations between the MLQ-P and the well-being scales, the average correlations for which were .38 (Time 1), .50 (Time 2), and .42 (Time 1 to Time 2).

To further establish discriminant validity, scores on the MLQ-P assessed with different methods (monotrait-heteromethod) should correlate more highly with each other than they do with scores on the well-being measures assessed using different methods (heterotrait-heteromethod). As reported previously, the correlations between self- and informant reports for the MLQ-P were .28 and .39. Correlations of self-reports with informant reports between the MLQ-P and well-being scales were in all cases lower (between .19 [Time 1] and .23 [Time 2], with a mean correlation of .21). These correlations were also lower than the heteromethod correlations between the MLQ-P and the other meaning measures, which ranged between .27 (Time 1) and .34 (Time 2). Informant and both Time 1 and Time 2 self-report correlations were higher among the MLQ-P and other meaning measures than among the MLQ-P and other well-being measures in 91\% (87/96) of comparisons, supporting the discriminant validity of the MLQ-P. In contrast, only $51 \%$ (49/96) of these comparisons were successful for the PIL, and only 58\% (56/96) were successful for the LRI. This indicates a failure of these two measures to adequately discriminate from other well-being constructs.

Evidence from informant reports also supported the discriminant validity of the MLQ-P, with informant-informant correlations between the MLQ-P and the PIL (.30) and the LRI (.38) exceeding those between the MLQ-P and the SWLS (.25), RSET (.26), and LOT (.24). Thus, it appeared that the MLQ-P discriminated from other types of well-being even among informants. In contrast, the informant-informant correlations between the PIL and MLQ-P (.30) and LRI (.43) exceeded some of the correlations between the PIL and SWLS (.46), RSET (.40), and LOT (.32) for only two of six successful comparisons. The LRI did better, with informant-informant correlations with the MLQ-P (.38) and PIL (.43) exceeding or matching those with the SWLS (.36), RSET (.42), and LOT (.38) in all but one comparison.

A stringent test of discriminant validity suggested by Campbell and Fiske (1959) is a comparison between monotrait-heteromethod correlations (i.e., self-reports and informant reports for the same trait) and correlations with other traits measured by the same method (heterotrait-monomethod), reasoning that assessments of the same traits by different methods should be more similar than assessments of different traits by the same method (correlations that might share only method variance). We compared the correlation between Time 1 self-reports and informant reports for the MLQ-P both with concurrent self-report correlations between the MLQ-P and well-being measures and with the correlations among informant reports on the MLQ-P and on well-being measures. We also made parallel comparisons using Time 2 reports and informant reports. At Time 1 the self-informant correlation for the MLQ-P (.28) exceeded one of four self-report correlations and all four informant report correlations between the MLQ-P and well-being measures. At Time 2, the selfinformant correlation for the MLQ-P (.39) exceeded two of four self-report and all four informant report correlations between the MLQ-P and well-being measures, for an overall success rate of 11/16 at Times 1 and 2. Somewhat lower success rates were observed for the PIL (8/16) and LRI (10/16).

\section{Comparison of Meaning Measures}

In addition to differences in discriminant validity among the measures previously noted, the average concurrent correlations with well-being measures were much larger for the PIL (.70) and LRI (.68) than for the MLQ-P (.44). Thus, the PIL and LRI appeared to display excessive overlap with other measures of well-being, replicating previous results (Zika \& Chamberlain, 1987, 1992) and supporting criticisms of these measures (e.g., Dyck, 1987).

One strength of the PIL and LRI, however, appeared to be that average correlations between self-reports and informant reports were somewhat higher than for the MLQ-P (PIL mean $r=.43$, LRI mean $r=.50$, MLQ-P mean $r=.34$ ), and both the PIL and the LRI demonstrated excellent convergent validity overall. However, their discriminant validity was of questionable quality. In this regard, the MLQ is superior to previous scales.

\section{Convergent and Discriminant Validity for the $M L Q-S$}

Fewer analyses are provided for the MLQ-S because multiple measures of the search for meaning are not available. Thus, only basic convergent and discriminant validity evidence is presented.

Convergent validity of the $M L Q-S$. Evidence of convergent validity for the MLQ-S was provided by the significant correlations between self- and informant reports on the MLQ-S at Time 1 (.31) and Time 2 (.35).

Discriminant validity of the $M L Q-S$. Discriminant validity is supported when correlations between self- and informant reports for the MLQ-S exceed heteromethod correlations with other measures. The average correlation between self- and informant reports 
on the MLQ-S was .33. These correlations were higher than the self-informant correlations between the MLQ-S and meaning and well-being measures $96 \%$ of the time, supporting the discriminant validity of this scale.

The more stringent test of discriminant validity compared monotrait-heteromethod correlations (self-informant correlations) on the MLQ-S with the heterotrait-monomethod correlations (e.g., within Time 1 self-reports or informant-informant correlations) between the MLQ-S and other measures. Most (88\%) of these comparisons favored the discriminant validity of the MLQ-S.

\section{Summary}

Study 3 supported the convergent and discriminant validity of both MLQ subscales. The MLQ-P was also shown to have better discriminant validity than two often-used meaning measures.

\section{General Discussion}

Evidence from three studies demonstrates that the two subscales of the MLQ appear to represent reliable, structurally sound measures of the presence of meaning and the search for meaning. First, in contrast to other meaning measures, the factor structure of the MLQ was replicated in two independent samples using CFA. The relative independence of the two subscales, as well as their differing patterns of correlations with other measures, means that for the first time, the presence of meaning can be assessed separately from the search for meaning. Second, the Presence subscale correlates as expected with a number of well-being, personality, and religiosity variables. Furthermore, an MTMM matrix study demonstrated that the MLQ-P possesses better discriminant validity than the two most often used meaning measures, the PIL and the LRI. The MLQ-S also was supported as being a measure distinct from other aspects of well-being and meaning.

In sum, the MLQ represents a number of improvements over existing measures of meaning, including more precise measurement, greater structural stability, and assessment of the search for meaning. As a final benefit, especially to large-scale or longitudinal studies or therapeutic outcome uses, the MLQ subscales contain only five items yet have demonstrated psychometric properties comparable or superior to those of longer meaning in life scales. The high convergent correlations (.61-.74) between the MLQ-P and other meaning measures indicate that they are tapping the same construct. Thus, given its brevity and unconfounded measurement of meaning, the MLQ appears to be a superior choice for exploring the theoretical space and functioning of meaning in life.

The principal benefit of using better measurement in the investigation of meaning in life is that it enables more accurate estimation of the true relationship between meaning and related constructs. For instance, one finding common to both the LRI and the PIL is that people's levels of reported meaning appear to increase following psychotherapy. Until now, it has been impossible to untangle the contributions made to these changes in meaning by reduced depression or anxiety, or increased life satisfaction, or any of the other constructs that have been cited as potential confounds. Study 3 indicates that the MLQ is free of inordinate covariance with several other measures of well-being. Additional correlations presented indicate that the MLQ is not excessively correlated with affect, religiosity, and values or depression, anxiety, and hostility.
Meaning in life can be viewed as a correlate, component, cause, or outcome of well-being. Without the ability to measure distinct constructs, our ability to explore their theoretical and causal spaces is severely hampered (see Kashdan, 2004, for a similar discussion regarding subjective well-being measurement).

The studies presented here echo previous findings that feeling one's life is meaningful is important to human functioning. In these and other studies (e.g., Weinstein \& Cleanthous, 1996; Zika \& Chamberlain, 1992) those who felt their life to be meaningful were less depressed and felt greater satisfaction with their lives, greater self-esteem and optimism, and more positive affect. In addition, those who experience meaning in their lives are more likely to be personally involved in their religious activities. Meaning seems to be an indicator of a healthy and appreciated life and deserves greater attention in empirical investigations of human functioning. A less clear picture emerges regarding those who are searching for meaning. Although the search for meaning has typically been characterized as a response to upsetting events (e.g., Thompson \& Janigian, 1988), it appears to have considerable variability in the present samples when assessed as a global construct. In addition, very little support was found for the widespread assumption that the search for meaning manifests only when one's life feels meaningless; instead, it was shown to be distinct and independent from the presence of meaning in life. Frankl (1965) and Maddi (1970) may be correct, however, when they suggest that frustration of the innate search for meaning in life may be distressing, as demonstrated by small to medium correlations between scores on the Search subscale and negative affect, depression, and neuroticism.

The ability of the MLQ to measure search and presence independently allows for greater theoretical and empirical flexibility. It is now possible to identify those who feel great meaningfulness yet still seek to further their understanding of life's meaning and compare them with those who feel their life is meaningful and are not engaged in any further search for meaning. For instance, Dietrich Bonhoeffer, Malcolm X, or Mahatma Gandhi may all exemplify lives in which great purpose and meaning did not foreclose the active and open pursuit for greater understanding of their meaning and purpose in the world. However, questions may remain about the true independence of the two constructs. Previously we discussed three possible explanations: that people might seek to add to their current sources of meaning, that they might want a deeper understanding of that which already makes their lives feel meaningful, and that they might seek new sources of meaning as existing ones fluctuate in significance.

Other examples exist in psychology wherein the search for and the attainment of a construct are independent. Among these are theories of identity formation. In his influential articulation of identity formation, Marcia (1966) used concepts of exploration and commitment (adapted from Erikson, 1968) as the axes of a two-dimensional space that describe the stages of identity development. In this model, individuals proceed from identity diffusion, in which they have neither explored nor committed to an identity, through identity foreclosure, in which they commit to an identity without exploring internally consonant alternatives, and identity moratorium, in which they are exploring possible identities without committing to any. Finally, individuals commit to some identity discerned through exploration, a stage called identity achievement. Models that predicate the necessity of an exploratory or searching stage have also been used in racial (e.g., 
Fischer, Tokar, \& Serna, 1998), ethnic (e.g., Sevig, Highlen, \& Adams, 2000), and sexual (e.g., Levine, 1997) identity research. One might argue that the development of meaning in life runs parallel to the development of identity and that some people may be at a stage of meaning diffusion (low presence, low search), meaning foreclosure (high presence, low search), meaning moratorium (low presence, high search), or meaning achievement (high presence, high search). To be consistent with the identity formation literature, in the case of meaning achievement, the implication is that people have searched in the past, although they may or may not still be searching for meaning.

Stage theories are vulnerable to criticisms, however, among which are the assumptions that people proceed through the stages in a specific order and that they cannot simultaneously be in more than one stage. Erikson used the term epigenesis to express the idea that successful resolution of later identity stages requires reexperiencing earlier stages, and that people also anticipate upcoming stages and tensions (Erikson, Erikson, \& Kivnick, 1986). Erikson also noted that even those who successfully resolved earlier stage crises may find that what worked at that time is inadequate for their present challenges. Vocational development theories also incorporate the idea of recycling through stages during transitions or in response to crisis (e.g., Super, 1990). With this in mind, one could theorize that those high in search for meaning are in a transitory state, with some experiencing a move from one satisfying lifestyle to another (high presence, high search), such as the anticipated birth of a child within a rewarding romantic relationship. Others may be faced with an existential crisis (low presence, high search), such as trying to recover from the death of a loved one. In fact, recent coping research has revealed that the search for meaning in a traumatic event is relatively independent from whether one has found meaning in that event (Davis, Wortman, Lehman, \& Silver, 2000). Among those who struggled to understand why they experienced trauma, arriving at a reason did not cause them to stop searching for meaning.

This latter finding suggests that there may be individual differences in the propensity to search for meaning in events. The data presented here are not able to address whether the statistical independence between presence and search is due to stable individual differences or developmental features. In either case, the interaction between the two constructs may have significant implications for well-being. For instance, in data reported elsewhere, a significant interaction between search and presence was found such that the presence of meaning in life was more important to life satisfaction for those searching for meaning, in both self-judgments and judgments of others (Steger \& Oishi, 2004). This gives some indication of the benefits of being able to assess both constructs.

\section{Implications for Counseling}

Accurate measurement is essential to psychological research. "Purified" measures of the presence of and search for meaning in life should benefit theory development in one of counseling's traditional foci, positive human functioning (Lent, 2004). In addition, the MLQ scales could be used to gather information at intake and assess successful therapy outcomes (cf. Gelso \& Woodhouse, 2003). For example, a significant portion of clients present with a desire for personal growth. The MLQ Search subscale can effectively gauge the extent to which clients seek greater purpose and meaning as part of this growth process. The majority of self- initiated counseling focuses on clients' efforts to recover their well-being or heal from aversive events or experiences (Lent, 2004). The MLQ Presence subscale provides an additional brief measure of psychological health, given both the pattern of inverse relations with common forms of psychological distress reported in the present studies (i.e., depression, anxiety) and the finding that a deeper appreciation of life (increased sense of life's meaning) is one of the most commonly reported positive outcomes of coping with adversity (Tedeschi, Park, \& Calhoun, 1998). The MLQ Presence subscale could also be used to assess the effectiveness of interventions designed to increase well-being. Given recent efforts by counseling psychologists to raise the profile of well-being (Lent, 2004; Robbins \& Kliewer, 2000; Walsh, 2003), as well as the formation of a "positive psychology" section within the Society for Counseling Psychology (Division 17 of American Psychological Association), the MLQ may be of timely assistance in helping forward these research and applied agendas.

\section{Limitations and Future Directions}

The development and validation of the MLQ do not answer all questions about the nature of meaning in life as a construct. We have provided a subjective measure that leaves open the question of what participants are considering when judging whether their lives are meaningful. Future research, using the MLQ as an index of meaning in life, should endeavor to identify the necessary constituents and precursors to developing meaning in life, and the bounds of its content space.

Limitations of the present studies also include the use of primarily convenience samples of Midwestern undergraduate psychology students, with the exception of the informant group from Study 3. Students may not be representative of all individuals. Meaning in life might play a larger role among older populations than among younger populations (see Wong, 1998). Clark and Watson (1995) stressed the importance of examining the factor structure of psychological assessment scales in heterogeneous samples. Such data would be beneficial to establish norms as well. Data collection is currently underway to address these concerns. Future research should also endeavor to access more diverse samples, because there has been very little cross-cultural work in this area. Some information is available regarding meaning in life within specific cultures (e.g., Hong Kong; see Shek, 1997), but there has been no systematic investigation of intra- and intercultural differences and similarities in meaning in life. Exploration of the sources of meaning for individuals in different cultures would be especially fruitful (see Bar-Tur, Savaya, \& Prager, 2001, for a comparison of Israeli Arabs and Jews on this topic).

In addition, with the exception of Study 3, only self-report methods were used in the present studies. To our knowledge, methodologies in the study of meaning in life have been limited to self-report, informant report (here), interviewer reports (PIL and LRI), criterion groups (PIL and LRI), and analysis of writing samples (e.g., Ebersole \& DeVogler-Ebersole, 1984). Additional methods, such as experience sampling, experimental manipulation, behavioral observation, and long interval longitudinal studies, could greatly inform our understanding of this construct.

Finally, little is known about how judgments of meaning in life are formed. Do they rely on stable personality characteristics, environmental or sociocultural contexts, mood, recent life events, 
or goal progress, to name a few potential candidates? The improved measure of meaning in life presented in this article should enable progress in these unexplored areas. The ability to measure meaning in life, without confounding with other constructs, using an instrument with good psychometric properties allows a more nuanced and accurate analysis of mediators, moderators, and correlates of meaning in life. Thus, we believe that the MLQ can contribute to the advance of well-being research, an important aspect of counseling psychology.

\section{References}

Allport, G. W. (1961). Pattern and growth in personality. New York: Holt, Rinehart \& Winston.

Antonovsky, A. (1987). Unraveling the mystery of health: How people manage stress and stay well. San Francisco: Jossey-Bass.

Arbuckle, J. L. (1999). AMOS 4.01. Chicago: SmallWaters Corp.

Bar-Tur, L., Savaya, R., \& Prager, E. (2001). Sources of meaning in life for young and old Israeli Jews and Arabs. Journal of Aging Studies, 15, 253-269.

Battista, J., \& Almond, R. (1973). The development of meaning in life. Psychiatry, 36, 409-427.

Baumeister, R. F. (1991). Meanings of life. New York: Guilford Press.

Bonebright, C. A., Clay, D. L., \& Ankenmann, R. D. (2000). The relationship of workaholism with work-life conflict, life satisfaction, and purpose in life. Journal of Counseling Psychology, 47, 469-477.

Bouchard, T. J., Jr., McGue, M., Lykken, D., \& Tellegen, A. (1999). Intrinsic and extrinsic religiousness: Genetic and environmental influences and personality correlates. Twin Research, 2, 88-98.

Browne, M. W., \& Cudeck, R. (1993). Alternative ways of assessing model fit. In K. A. Bollen \& J. S. Long (Eds.), Testing structural equation models (pp. 136-162). Newbury Park, CA: Sage.

Campbell, D. T., \& Fiske, D. W. (1959). Convergent and discriminant validation by the multitrait-multimethod matrix. Psychological Bulletin, $56,81-105$.

Chamberlain, K., \& Zika, S. (1988a). Measuring meaning in life: An examination of three scales. Personality and Individual Differences, 9, $589-596$.

Chamberlain, K., \& Zika, S. (1988b). Religiosity, life meaning, and wellbeing: Some relationships in a sample of women. Journal for the Scientific Study of Religion, 27, 411-420.

Clark, L. A., \& Watson, D. (1995). Constructing validity: Basic issues in objective scale development. Psychological Assessment, 7, 309-319.

Cohen, J. (1992). A power primer. Psychological Bulletin, 112, 155-159.

Comrey, A. L. (1988). Factor-analytic methods of scale development in personality and clinical psychology. Journal of Consulting and Clinical Psychology, 56, 754-761.

Cronbach, L. J., \& Meehl, P. E. (1955). Construct validity in psychological tests. Psychological Bulletin, 52, 281-302.

Crowne, D. P., \& Marlow, D. (1960). A new scale of social desirability independent of psychopathology. Journal of Consulting Psychology, 24, 349-354.

Crumbaugh, J. C. (1977). The Seeking of Noetic Goals Test (SONG): A complementary scale to the Purpose in Life Test (PIL). Journal of Clinical Psychology, 33, 900-907.

Crumbaugh, J. C., \& Maholick, L. T. (1964). An experimental study in existentialism: The psychometric approach to Frankl's concept of noogenic neurosis. Journal of Clinical Psychology, 20, 200-207.

Davis, C. G., Wortman, C. B., Lehman, D. R., \& Silver, R. C. (2000). Searching for meaning in loss: Are clinical assumptions correct? Death Studies, 24, 497-540.

Dawis, R. (2000). Scale construction and psychometric considerations. In H. E. A. Tinsley \& S. D. Brown (Eds.), Handbook of applied multivar- iate statistics and mathematical modeling (pp. 65-94). San Diego, CA: Academic Press.

Day, S., \& Rottinghaus, P. (2003). The healthy personality. In W. B. Walsh (Ed.), Counseling psychology and optimal human functioning (pp. 1-23). Mahwah, NJ: Erlbaum.

Debats, D. L., van der Lubbe, P. M., \& Wezeman, F. R. A. (1993). On the psychometric properties of the Life Regard Index (LRI): A measure of meaningful life. Personality and Individual Differences, 14, 337-345.

Deci, E. L., \& Ryan, R. M. (2000). The "what" and "why" of goal pursuit: Human needs and the self-determination of behavior. Psychological Inquiry, 11, 227-268.

Derogatis, L. R., \& Spencer, M. S. (1992). The Brief Symptom Inventory (BSI) administration, scoring, and procedures manual-I. Baltimore: Johns Hopkins University School of Medicine, Clinical Psychometrics Unit.

Diener, E., Emmons, R. A., Larsen, R. J., \& Griffin, S. (1985). The Satisfaction With Life Scale. Journal of Personality Assessment, 49, $71-75$.

Diener, E., Smith, H., \& Fujita, F. (1995). The personality structure of affect. Journal of Personality and Social Psychology, 69, 130-141.

Dilalla, L. F. (2000). Structural equation modeling: Uses and issues. In H. E. A. Tinsley \& S. D. Brown (Eds.), Handbook of applied multivariate statistics and mathematical modeling (pp. 439-464). San Diego, CA: Academic Press.

Dyck, M. J. (1987). Assessing logotherapeutic constructs: Conceptual and psychometric status of the Purpose in Life and Seeking of Noetic Goals Tests. Clinical Psychology Review, 7, 439-447.

Ebersole, P., \& DeVogler-Ebersole, K. (1984). Depth of meaning in life and literary preference. Psychology: A Journal of Human Behavior, 21, $28-30$.

Erikson, E. H. (1968). Identity: Youth and crisis. New York: Norton.

Erikson, E. H., Erikson, J. M., \& Kivnick, H. Q. (1986). Vital involvement in old age: The experience of old age in our time. New York: Norton.

Finch, J. F., \& West, S. G. (1997). The investigation of personality structure: Statistical models. Journal of Research in Personality, 31, 439-485.

Fischer, A. R., Tokar, D. M., \& Serna, G. S. (1998). Validity and construct contamination of the Racial Identity Attitude Scale-Long Form. Journal of Counseling Psychology, 45, 212-224.

Floyd, F. J., \& Widaman, K. F. (1995). Factor analysis in the development and refinement of clinical assessment instruments. Psychological Assessment, 7, 286-299.

Frankl, V. E. (1963). Man's search for meaning: An introduction to logotherapy. New York: Washington Square Press.

Frankl, V. E. (1965). The doctor and the soul: From psychotherapy to logotherapy. New York: Vintage Books.

Frankl, V. E. (1966). What is meant by meaning? Journal of Existentialism, 7, 21-28.

Frazier, P., Oishi, S., \& Steger, M. (2003). Assessing optimal human functioning. In W. B. Walsh (Ed.), Counseling psychology and optimal human functioning (pp. 251-278). Mahwah, NJ: Erlbaum.

Garfield, C. (1973). A psychometric and clinical investigation of Frankl's concept of existential vacuum and anomie. Psychiatry, 36, 396-408.

Gelso, C. J., \& Woodhouse, S. (2003). Toward a positive psychotherapy: Focus on human strength. In W. B. Walsh (Ed.), Counseling psychology and optimal human functioning (pp. 171-197). Mahwah, NJ: Erlbaum.

Gorsuch, R. L., \& McPherson, S. E. (1989). Intrinsic/extrinsic measurement: I/E-Revised and single item scales. Journal for the Scientific Study of Religion, 28, 348-354.

Harlow, L. L., Newcomb, M. D., \& Bentler, P. M. (1986). Depression, self-derogation, substance use, and suicide ideation: Lack of purpose in life as a mediational factor. Journal of Clinical Psychology, 42, 5-21.

Harris, A. H. S., \& Standard, S. (2001). Psychometric properties of the Life Regard Index-Revised: A validation study of a measure of personal meaning. Psychological Reports, 89, 759-773. 
Harris, A. H. S., \& Thoresen, C. E. (2003). Strength-based health psychology: Counseling for total human health. In W. B. Walsh (Ed.), Counseling psychology and optimal human functioning (pp. 199-227). Mahwah, NJ: Erlbaum.

Kashdan, T. B. (2004). The assessment of subjective well-being (issues raised by the Oxford Happiness Questionnaire). Personality and Individual Differences, 36, 1225-1232.

Kenyon, G. M. (2000). Philosophical foundations of existential meaning. In G. T. Reker \& K. Chamberlain (Eds.), Exploring existential meaning: Optimizing human development across the life span (pp. 7-22). Thousand Oaks, CA: Sage.

Keyes, C. L. M., Shmotkin, D., \& Ryff, C. D. (2002). Optimizing wellbeing: The empirical encounter of two traditions. Journal of Personality and Social Psychology, 82, 1007-1022.

Klinger, E. (1977). Meaning and void. Minneapolis: University of Minnesota Press.

Lent, R. W. (2004). Toward a unifying theoretical and practical perspective on well-being and psychosocial adjustment. Journal of Counseling Psychology, 51, 482-509.

Levine, H. (1997). A further exploration of the lesbian development process and its measurement. Journal of Homosexuality, 34, 67-78.

Lucas, R. E., Diener, E., \& Suh, E. (1996). Discriminant validity of well-being measures. Journal of Personality and Social Psychology, 71, $616-628$

Lyubomirsky, S., \& Lepper, H. S. (1999). A measure of subjective happiness: Primary reliability and construct validation. Social Indicators Research, 46, 137-155.

Maddi, S. R. (1970). The search for meaning. In M. Page (Ed.), Nebraska Symposium on Motivation (pp. 137-186). Lincoln: University of Nebraska Press.

Malloy, T. E., Albright, L., Kenny, D. A., Agatstein, F., \& Winquist, W. (1997). Interpersonal perception and metaperception in nonoverlapping social groups. Journal of Personality and Social Psychology, 72, 390-398.

Marcia, J. L. (1966). Development and validation of ego-identity status. Journal of Personality and Social Psychology, 3, 351-358.

Maslow, A. H. (1971). The further reaches of human nature. New York: Viking.

McAdams, D. P. (1993). The stories we live by: Personal myths and the making of the self. New York: Morrow.

McGregor, I., \& Little, B. R. (1998). Personal projects, happiness, and meaning: On doing well and being yourself. Journal of Personality and Social Psychology, 74, 494-512.

Moreland, K. L. (1985). Review of Seeking of Noetic Goals Test. In J. V. Mitchell Jr. (Ed.), The ninth mental measurements yearbook (pp. 13391340). Lincoln: University of Nebraska Press.

Oishi, S., Diener, E., Suh, E., \& Lucas, R. E. (1999). Value as a moderator in subjective well-being. Journal of Personality, 67, 157-184.

Park, C. L., \& Folkman, S. (1997). Meaning in the context of stress and coping. Review of General Psychology, 30, 115-144.

Pavot, W. G., \& Diener, E. (1993). Review of the satisfaction with life scale. Psychological Assessment, 5, 164-172.

Reise, S. P., Waller, N. G., \& Comrey, A. L. (2000). Factor analysis and scale revision. Psychological Assessment, 12, 287-297.

Reker, G. T. (1992). Manual: Life Attitude Profile-Revised. Petersborough, Ontario, Canada: Student Psychologists Press.

Reker, G. T., \& Cousins, J. B. (1979). Factor structure, construct validity and reliability of the Seeking of Noetic Goals (SONG) and Purpose in Life (PIL) Tests. Journal of Clinical Psychology, 35, 85-91.

Reker, G. T., \& Fry, P. S. (2003). Factor structure and invariance of personal meaning measures in cohorts of younger and older adults. Personality and Individual Differences, 35, 977-993.

Reker, G. T., \& Peacock, E. J. (1981). The Life Attitude Profile (LAP): A multidimensional instrument for assessing attitudes toward life. Canadian Journal of Behavioral Science, 13, 264-273.
Reker, G. T., \& Wong. P. T. P. (1988). Aging as an individual process: Toward a theory of personal meaning. In J. E. Birren \& V. L. Bengston (Eds.), Emergent theories of aging (pp. 214-246). New York: Springer.

Robbins, S. B., \& Kliewer, W. L. (2000). Advances in theory and research on subjective well-being. In S. D. Brown \& R. W. Lent (Eds.), Handbook of counseling psychology (pp. 310-345). New York: Wiley.

Rosenberg, M. (1965). Society and the adolescent self-image. Princeton, NJ: Princeton University Press.

Ryan, R. M., \& Deci, E. L. (2001). On happiness and human potentials: A review of research on hedonic and eudaimonic well-being. Annual Review of Psychology, 52, 141-166.

Ryff, C. D. (1989). Happiness is everything, or is it? Explorations on the meaning of psychological well-being. Journal of Personality and Social Psychology, 57, 1069-1081.

Ryff, C. D., \& Singer, B. (1998). The contours of positive human health. Psychological Inquiry, 9, 1-28.

Sammallahti, P. R., Holi, M. J., Komulainen, E. J., \& Aalberg, V. A. (1996). Comparing two self-report measures of coping - the Sense of Coherence Scale and the Defense Styles Questionnaire. Journal of Clinical Psychology, 52, 517-524.

Sandvik, E., Diener, E., \& Siedlitz, L. (1993). Subjective well-being: The convergence and stability of self-report and non-self-report measures. Journal of Personality, 61, 317-342.

Saucier, G. (1994). Mini-markers: A brief version of Goldberg's Unipolar Big Five Markers. Journal of Personality Assessment, 63, 506-516.

Savickas, M. L. (2003). Toward a taxonomy of human strengths: Career counseling's contribution to positive psychology. In W. B. Walsh (Ed.), Counseling psychology and optimal human functioning (pp. 229-249). Mahwah, NJ: Erlbaum.

Scheier, M. F., \& Carver, C. S. (1985). Optimism, coping, and health: Assessment and implications of generalized outcome expectancies. Health Psychology, 4, 219-247.

Schwartz, S. H., \& Sagiv, L. (1995). Identifying culture-specifics in the content and structure of values. Journal of Cross-Cultural Psychology, 26, 92-116.

Seligman, M. E. P. (2002). Authentic happiness. New York: Free Press.

Seligman, M. E. P., \& Csikszentmihalyi, M. (2000). Positive psychology: An introduction. American Psychologist, 55, 5-14.

Sevig, T. D., Highlen, P. S., \& Adams, E. M. (2000). Development and validation of the Self-Identity Inventory (SII): A multicultural identity development instrument. Cultural Diversity \& Ethnic Minority Psychology, 6, 168-182.

Shek, D. T. L. (1997). Family environment and adolescent psychological well-being, school adjustment, and problem behavior: A pioneer study in a Chinese context. Journal of Genetic Psychology, 158, 113-128.

Steger, M. F., \& Oishi, S. (2004). Is a life without meaning satisfying? The moderating role of the search for meaning in life satisfaction judgments. Manuscript submitted for publication.

Super, D. E. (1990). A life-span, life-space approach to career development. In D. Brown \& L. Brooks (Eds.), Career choice and development: Applying contemporary theories to practice (2nd ed.). San Francisco: Jossey-Bass.

Tedeschi, R. G., Park, C. L., \& Calhoun, L. G. (1998). Posttraumatic growth: Conceptual issues. In R. G. Tedeschi, C. L. Park, \& L. G. Calhoun (Eds.), Posttraumatic growth: Theory and research on change in the aftermath of crisis (pp. 1-22). Mahwah, NJ: Erlbaum.

Thompson, S. C., \& Janigian, A. S. (1988). Life schemes: A framework for understanding the search for meaning. Journal of Social and Clinical Psychology, 7, 260-280.

Ullman, J. B. (2001). Structural equation modeling and confirmatory factor analysis. In B. G. Tabachnick \& L. S. Fidell (Eds.), Using multivariate statistics (pp. 653-771). Boston: Allyn \& Bacon.

Van Wicklin, J. F. (1990). Conceiving and measuring ways of being religious. Journal of Psychology and Religion, 9, 27-40. 
Visser, P. S., Krosnick, J. A., \& Lavrakas, P. J. (2000). Survey research. In H. T. Reis \& C. M. Judd (Eds.), Handbook of research methods in social and personality psychology (pp. 223-252). New York: Cambridge University Press.

Walsh, W. B. (Ed.). (2003). Counseling psychology and optimal human functioning. Mahwah, NJ: Erlbaum.

Watson, D., Clark, L. A., \& Tellegen, A. (1988). Development and validation of brief measures of positive and negative affect: The PANAS scales. Journal of Personality and Social Psychology, 54, 1063-1070.

Weinstein, L., \& Cleanthous, C. C. (1996). A comparison of protestant ministers and parishioners on expressed purpose in life and intrinsic religious motivation. Psychology: A Journal of Human Behavior, 33, 26-29.

Wong, P. T. P. (1998). Spirituality, meaning, and successful aging. In
P. T. P. Wong \& P. S. Fry (Eds.), The human quest for meaning: A handbook of psychological research and clinical application (pp. 111140). Mahwah, NJ: Erlbaum.

Wong, P. T. P., \& Fry, P. S. (1998). The human quest for meaning: A handbook of psychological research and clinical application. Mahwah, NJ: Erlbaum.

Yalom, I. D. (1980). Existential psychotherapy. New York: Basic Books. Zika, S., \& Chamberlain, K. (1987). Relation of hassles and personality to subjective well-being. Journal of Personality and Social Psychology, 53, $155-162$.

Zika, S., \& Chamberlain, K. (1992). On the relation between meaning in life and psychological well-being. British Journal of Psychology, 83, $133-145$.

\section{Appendix}

\section{The Meaning in Life Questionnaire}

MLQ Please take a moment to think about what makes your life feel important to you. Please respond to the following statements as truthfully and accurately as you can, and also please remember that these are very subjective questions and that there are no right or wrong answers. Please answer according to the scale below:

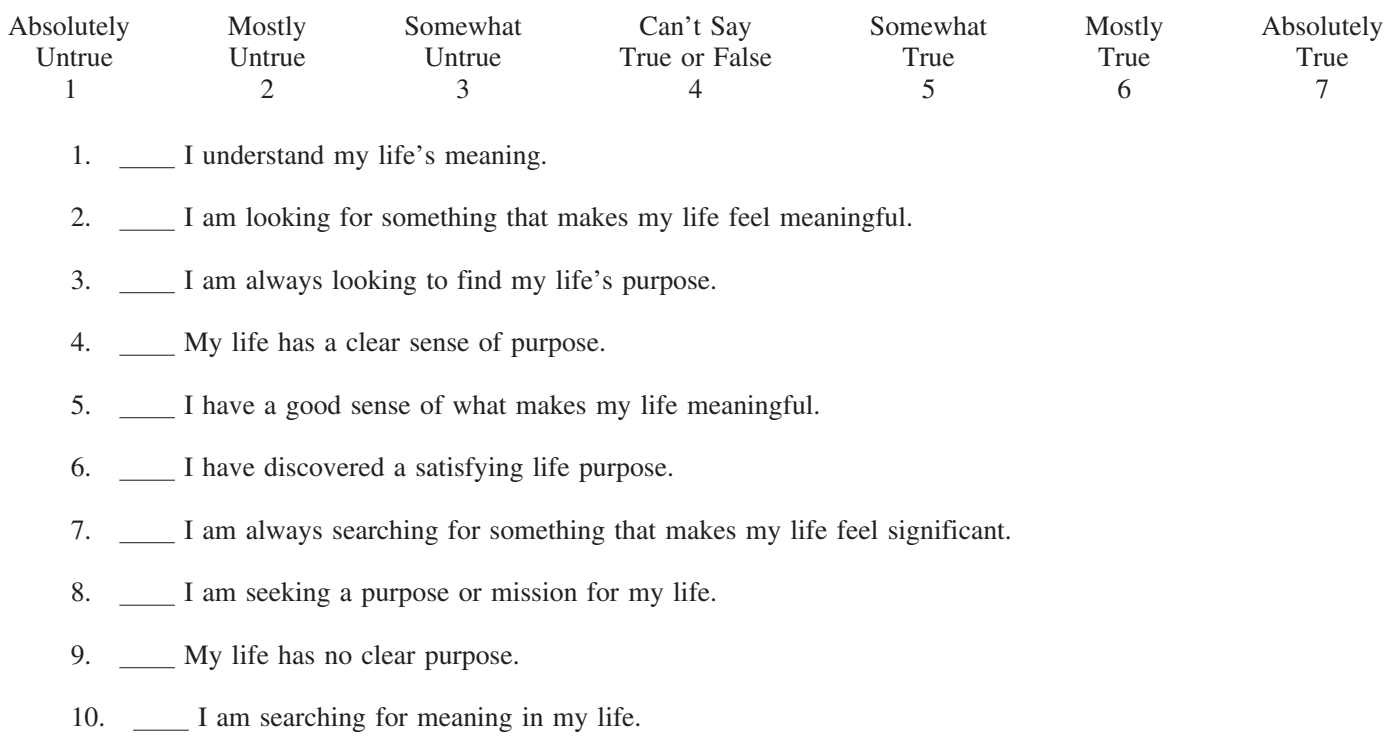

MLQ syntax to create Presence and Search subscales:

Presence $=1,4,5,6, \&$ 9-reverse-coded

Search $=2,3,7,8, \& 10$

The copyright for this questionnaire is owned by the University of Minnesota. This questionnaire is intended for free use in research and clinical applications. Please contact Michael F. Steger prior to any such noncommercial use. This questionnaire may not be used for commercial purposes.

Received December 23, 2004

Revision received March 29, 2005

Accepted March 30, 2005 